\title{
STATUS REFINEMENT OF METAL-POOR STAR HD 6268
}

\author{
T. Mishenina ${ }^{1}$, I. Usenko ${ }^{1,2}$, A. Kniazev ${ }^{3}$, V. Kovtyukh ${ }^{1}$ \\ ${ }^{1}$ Astronomical Observatory, Odessa National University, 65014-UA Odessa, Ukraine, \\ tmishenina@ukr.net \\ 2 Mykolaiv Astronomical Observatory, Obsevatorna 1,Mykolaiv 54030, Ukraine \\ ${ }^{3}$ South African Astronomical Observatory, P.O. 7925, Cape Town, South Africa
}

\begin{abstract}
Metal-poor stars in the Galaxy enable observations of the light and neutron-capture (n-capture) elements produced by their progenitors and deduction of the characteristics of the early Galaxy from the elemental abundances in these stars. Stars with deficiency of metals $([\mathrm{Fe} / \mathrm{H}]<-2)$ vary significantly in their chemical composition, in particular, in their content of CNO elements, as well as the iron-peak and n-capture elements. A detailed study of the elemental abundances in these stars makes it possible to test experimental models of stellar evolution, nucleosynthesis, homogeneity (the degree of mixing) of interstellar matter, etc., at low metallicity in the Galaxy.
\end{abstract}

The metal-poor star HD 6268 with $[\mathrm{Fe} / \mathrm{H}]$ close to 2.5 and low carbon abundance was selected as a target one for this study. The spectral material was collected using the Southern African Large Telescope (SALT) fibre-fed echelle-spectrograph HRS in the medium resolution mode ( $\mathrm{R} \sim 31000-41000)$ with a high $\mathrm{S} / \mathrm{N}$ ratio near $100-200$ within the range from 3900 to $8700 \AA \AA$. The atmospheric stellar parameters and abundances of 30 chemical elements in the metal-poor star HD 6268 were determined under the LTE approximation using the atmosphere models by Kurucz \& Castelli (2003), as well as the equivalent widths EWs and WIDH9 code developed by Kurucz. The abundances of C, Na, Mg, K, Ba, La, Ce, Pr, Sm and Eu were obtained by the synthetic spectrum method factoring in the hyperfine structure (HFS) for the Eu II line 4129 A. The carbon abundance was determined by the molecular synthesis fitting in the region of $\mathrm{CH}$ (4300-4330 $\AA \AA$ ). For the abundances of $\mathrm{Na}, \mathrm{Mg}, \mathrm{K}$ and $\mathrm{Ba}$, we applied the NLTE corrections.

As a result, we found out that the abundances of $\mathrm{C}$ and $\mathrm{N}$ confirm their changes associated with canonical extra mixing proposed by Denissenkov \& Pinsonneault (2008). The Na-O correlation is open to question unlike the $\mathrm{Na}-\mathrm{Si}$ correlation which is likely to exist. The Al-Mg and Al-Na correlations are consistent with the data obtained for the field giants with $[\mathrm{C} / \mathrm{Fe}]<-0.5$ (Roederer et al., 2014).

According to the distribution of elements depending on their atomic numbers in the atmosphere of HD 6268, it is a metal-poor main r-process enriched star.

Keywords: stars: abundances - stars: atmospheres - stars: Population II - stars: individual: HD 6268
АБСТРАКТ. Бідні металами зорі Галактики дають змогу спостерігати легкі елементи та елементи нейтронного захвату, що вироблені їхніми зорямипопередниками, і через їх вміст вивести характеристики ранньої Галактики. Зорі 3 дефіцитом металів $([\mathrm{Fe} / \mathrm{H}]<-2)$ показують помітну різноманітність хімічного складу, це стосується як $\mathrm{CNO}$-елементів, так і елементів залізного піку та n-захвату. Детальне вивчення вмісту елементів у цих зорях дозволяє перевіряти (тестувати) моделі зоряної еволюції, нуклеосинтезу, однорідності (ступінь змішування) міжзоряної речовини тощо при низькій металічності в Галактиці.

Малометаллічна зоря HD 6268 з [Fe/H] близько $-2,5$ i малим вмістом вуглецю була вибраноа для нашого дослідження. Спектральний матеріал був отриманий 3 ешеле-спектрографом $\mathrm{HRS}$, який розміщений на Південно-Африканському Великому Телескопі (SALT) в режимі середньої роздільної здатності $(\mathrm{R} \sim 31000$ 41000) 3 високим співвідношенням сигнал/шум (S/N близько 100-200) у діапазоні від 3900 до 8700 АА. Зоряні параметри та вміст 30 хімічних елементів в атмосфері HD 6268 були визначені в наближенні локальної термодинамічної рівноваги (ЛТР), використовуючи моделі атмосфери Куруца та Кастеллі (2003), еквівалентні ширини EW ліній та код WIDH9 Куруча. Вміст C, Na, Mg, K, Ba, La, Ce, Pr, Sm, Eu, отримано методом синтетичного спектру 3 урахуванням надтонкої структури (HFS) для лінії Eu II 4129 А. Вміст вуглецю визначався за молекулярним синтезом пристосування профілей в районі СН (43004330 А). Для вмісту $\mathrm{Na}, \mathrm{Mg}, \mathrm{K}$, Ва ми використовували виправлення (корекціі) за рахунок відхилень від ЛТР.

3 отриманих результатів було виявлено, що вмісти вуглецю C і та азоту $\mathrm{N}$ підтверджують, що зміни їх вмісту відбулися шляхом канонічного додаткового змішування, запропонованого Денисенковим і Пінсоннео (2008); наявність співвідношення $\mathrm{Na}-\mathrm{O}$ під сумнівом, на відміну від співвідношення $\mathrm{Na}-\mathrm{Si}$, що може бути. Відношення Al-Mg, Al-Na співпадають 3 даними, отриманими для гігантів галактичного поля 3 $[\mathrm{C} / \mathrm{Fe}]<-0.5$ (Roederer et al., 2014).

HD $6268 \epsilon$ зорею, яка демонструє збагачення основним r-процесом відповідно до розподілу вмісту елементів $з$ атомним номером в іiі атмосфері.

Ключові слова: зірки: вміст хімічних елементів зірки: атмосфери - зірки: Населення II - зірки: індивідуальні: HD 6268 


\section{Introduction}

Metal-poor stars in the Galaxy enable us to observe CNO elements, as well as the alpha-, iron-peak and neutron-capture (n-capture) elements, produced by their progenitors and deduce the evolution and features of the early Galaxy from the abundances in these stars.

Besides, the stars in the advanced stages of their evolution (e.g. giants, AGB stars, etc.) allow us studying peculiarities of stellar evolution at low metallicity. Stars with deficiency of metals $([\mathrm{Fe} / \mathrm{H}]<-2)$ vary significantly in their chemical composition, in particular, in their content of $\mathrm{CNO}$ and n-capture elements (e.g., McWilliam et al.,1995; Burris et al., 2000; Sneden et al., 2003; Honda et al., 2006; Frebel et al., 2008; Roederer et al., 2014, etc.). While the carbon deficiency and excess of nitrogen detected in giants has been traditionally interpreted within the framework of their own evolution, a lot of attention has been paid recently to the stars enriched in carbon, such as carbon-enhanced metal-poor stars (CEMP).

The star HD 6268 does not exhibit any excess of carbon; the contrary is the case as it is a giant with underabundant carbon and overabundant nitrogen having $[\mathrm{Fe} / \mathrm{H}]$ of about 2.5 (see, e.g., McWilliam et al, 1995; Roedeter et al., 2014), which is likely due to the mixing processes within the star, as well as due to different mechanisms of matter transfer over the course of its evolution.

In this regard, it is very important to analyse the chemical composition and, in particular, the correlation of $\mathrm{CNO}$ elements with $\mathrm{Na}, \mathrm{Mg}$ and $\mathrm{Al}$, whose abundances change as a result of nuclear reactions and hydrogen burning in the advanced cycles (e.g., Gratton et al., 2000; Spite et al., 2006). Stellar models predict that as a low mass star evolves up the red-giant branch (RGB), the outer convective envelope expands inward and penetrates into the $\mathrm{CN}$-cycle processed inner regions. The ensuing mixing episode, called the first dredge-up, is expected to alter the abundance of light elements on the star's surface (Iben, 1964).

The first dredge up is expected to be less efficient in metal-poor stars (VandenBerg \& Smith, 1988; Charbonnel, 1994): the $\mathrm{C}$ and $\mathrm{N}$ abundances change insignificantly, and the $12 \mathrm{C} / 13 \mathrm{C}$ ratio is expected to remain $>30$. The theoretical studies (e.g., Charbonnel, 1994; 1995) have demonstrated that some further mixing is possible in the latest phases of the RGB: in fact, after the end of the dredge-up phase is reached, the convective envelope begins to recede, leaving behind a chemical discontinuity; the corresponding change in molecular weight prevents further mixing.

In this study, we have investigated the atmospheric parameters and elemental abundances in HD 6268 aiming at clarifying its status on the basis of accurate determination of its chemical composition.

\section{Observations and spectrum processing, radial ve-} locities

The main characteristics of HD 6268 (HIP 4933) were taken from the SIMBAD database, in particular: Equatorial coordinates: $\alpha=010318 ; \delta=-275249$ (2000) (GAIA DR2); Galactic coordinates: 229.57; -87.26 (2000).
Stellar magnitudes: $\mathrm{B}=9.725 ; \mathrm{V}=9.046$ (Zacharias et al., 2012; UCAC4); distance $=705.9156$ pc (GAIA DR2); parallax (mas): 1.4166 [0.0440] (GAIA DR2); radial velocity (RV) in $\mathrm{km} / \mathrm{s}=39.52$ [0.15] (GAIA DR2).

The spectral material for the target star was collected in 2017 with the 11-metre Southern African Large Telescope (SALT) fibre-fed echelle-spectrograph HRS. The spectra were obtained in the medium resolution mode $(\mathrm{R} \sim 31000$ 41000 ) with a high $\mathrm{S} / \mathrm{N}$ ratio near $100-200$ within the range from 3900 to $8700 \AA \AA$. All the data were processed using the software package developed by the authors based on the standard system of astronomical data reduction MIDAS. Further spectra processing, such as the continuum establishment, line depth and equivalent width (EW) measurements, etc., was conducted using the DECH30 software package by G.A. Galazutdinov (2007).

\section{Determination of parameters}

We used spectroscopic methods for determination of the stellar parameters of HD6268, because we found out a contradiction in the photometric data, in particular, the stellar magnitude $\mathrm{V}$ obtained earlier in the Johnson system $(\mathrm{V}=8.16)$ differed from the latest value $\mathrm{V}=9.046$ given in the SIMBAD database (Zacharias et al., UCAC4). Nevertheless, in the first approximation, in order to determine the effective temperature $\mathrm{T}_{\text {eff }}$ of the target star, we used the photometric data $(\mathrm{V}=8.16$ and $\mathrm{B}-\mathrm{V}=0.813)$ and photometric calibration given in McWilliam et al. (1995). Then, we refined the $\mathrm{T}_{\text {eff }}$ value based on the independence of the iron abundance determined from a given line on the lower-level potential $\mathrm{E}_{\text {low }}$ of that line (Fig. 1). To determine the gravity $\log \mathrm{g}$, we employed the iron ionisation balance technique for the Fe I and Fe II abundances. The microturbulent velocity $\mathrm{V}_{\mathrm{t}}$ was determined from the condition of independence of the iron abundance determined from a given line on its equivalent width EW (Fig. 2).

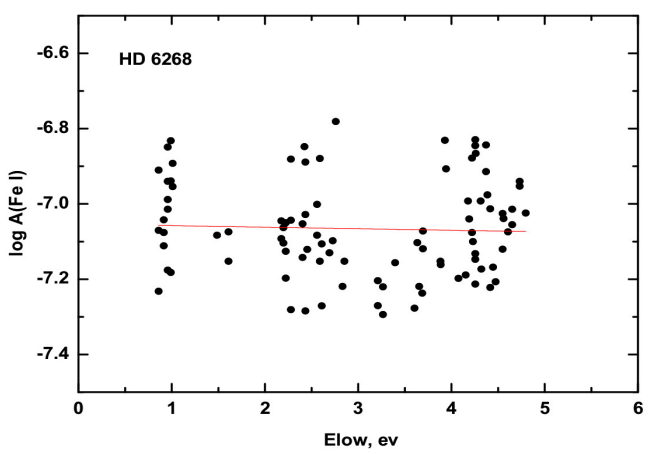

Figure 1: The dependence of $\log \mathrm{A}(\mathrm{Fe} \mathrm{I})$ on $\mathrm{E}_{\text {low }}$

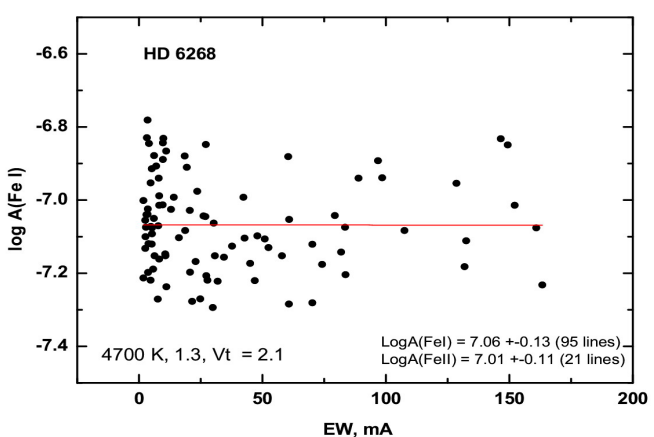

Figure 2: The dependence of $\log \mathrm{A}(\mathrm{FeI})$ on $\mathrm{EW}$ 
Table 1. Parameter's comparison with those obtained in different papers

\begin{tabular}{|l|l|l|l|l|}
\hline $\mathbf{T}_{\text {eff }}$ & $\log \mathbf{g}$ & $\mathbf{F e} / \mathbf{H}]$ & $\begin{array}{l}\mathbf{V t}, \\
\mathbf{k m} / \mathbf{s}\end{array}$ & reference \\
\hline 4700 & 1.3 & -2.56 & 2.1 & our \\
\hline 4818 & 0.84 & -2.40 & 1.5 & Gratton, 1989 \\
\hline 4670 & 0.75 & -2.58 & 2.73 & $\begin{array}{l}\text { McWilliam et al., } \\
1995\end{array}$ \\
\hline 4700 & 1.6 & -2.36 & 1.3 & $\begin{array}{l}\text { Pilachowski et al., } \\
1996\end{array}$ \\
\hline 4800 & 0.84 & -2.56 & 2.5 & Francois, 1996 \\
\hline 4700 & 1.6 & -2.36 & 1.6 & Burris et al., 2000 \\
\hline 4740 & 1.20 & -2.32 & - & Cenarro et al., 2007 \\
\hline 4696 & 1.2 & -2.74 & - & Yong et al., 2013 \\
\hline 4570 & 0.70 & -2.89 & 1.85 & Roederer et al., 2014 \\
\hline 4696 & 1.2 & -2.74 & 2.75 & Placco et al., 2014 \\
\hline 4726 & 1.14 & -2.63 & 2.05 & Wu et al., 2015 \\
\hline
\end{tabular}

The metallicity $[\mathrm{Fe} / \mathrm{H}]$ was adopted as the iron abundance determined from the Fe I lines. The selection of the parameters was performed using an iterative procedure. Finally, the following parameters were adopted: $\mathrm{T}_{\text {eff }}=$ $4700 \mathrm{~K} ; \log \mathrm{g}=1.3 ; \mathrm{V}_{\mathrm{t}}=2.1 \mathrm{~km} / \mathrm{s}$.

Table 1 presents the results of the comparison of our data with the findings of other researchers. As can be seen in Table 1 , there is a good agreement between $\mathrm{T}_{\text {eff }}$ and $[\mathrm{Fe} / \mathrm{H}]$ obtained by different authors. However, noticeable discrepancies can be observed for the gravity $\log g$ and turbulent velocity $\mathrm{V}_{\mathrm{t}}$.

Our determinations corroborate with the mean values of the parameters within the errors: $<$ Teff $>=4710 \pm 65$ $\mathrm{K} ;<\log \mathrm{g}>=1.12 \pm 0.30 ;<[\mathrm{Fe} / \mathrm{H}]>=-2.56 \pm 0.18 ;<\mathrm{Vt}>$ $=2.04 \pm 0.53 \mathrm{~km} / \mathrm{s}$.

It should be noted that for the metallicities close to that one of the target star, the deviations from the Local Thermodynamic Equilibrium (LTE) may influence the stellar parameters and iron abundance (see, e.g., Lind et al., 2012). However, Roederer et al. (2014) have investigated metalpoor stars and found out that the Fe II abundance determined by the LTE calculations is close to its estimates under non-LTE approximations within $0.02 \mathrm{dex}$. The obtained results enabled Roederer et al. (2014) to adopt the iron abundance derived from the Fe II lines as an indicator of metallicity $[\mathrm{Fe} / \mathrm{H}]$. The effect of the non-LTE deviations on the iron abundance determination from the Fe I lines is stronger, but it does not exceed 0.2 dex as reported by different authors (e.g., Thévenin \& Idiart, 1999; Asplund, 2005). Our estimates of the iron abundance obtained from the Fe I and Fe II lines are almost similar, hence our decision to take the $\mathrm{Fe} I$ abundance as $[\mathrm{Fe} / \mathrm{H}]$ does not contribute significantly to the error in determination of the parameters and iron abundance. To verify our log g determined by the Fe I/Fe II ionization balance, we adopted our estimated surface gravity $\log \mathrm{g}$ (as well as $\mathrm{T}_{\text {eff) }}$ in the theoretical isochrones in the Y2 grid (Demarque et al., 2004) for the relevant metallicity $([\mathrm{Fe} / \mathrm{H}]=-2.5)$. As can be seen, there is an agreement between our $\log g$ and the position in the corresponding theoretical track, which corroborates our gravity determination and allow us assuming the age of the target star to be 12 Gyr (Fig. 3).

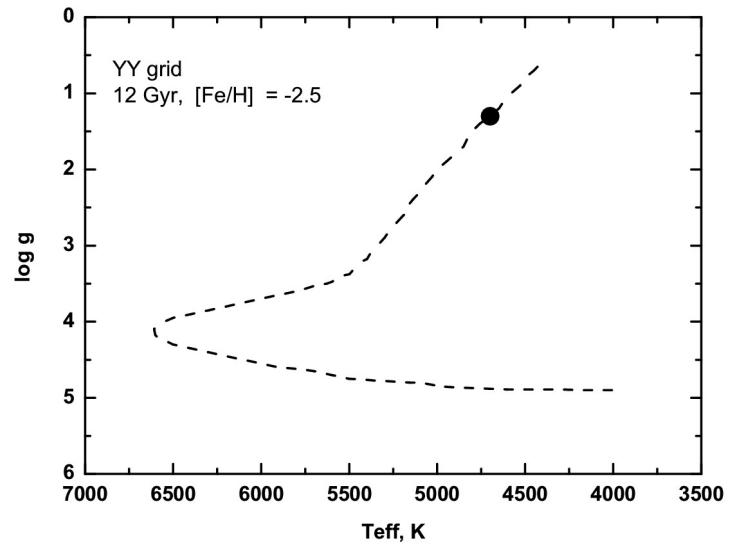

Figure 3: Position of HD 6258 on the theoretical isochrones of the Y2 grid (Demarque et al. 2004)

\section{Abundance determination}

For HD 6268, the abundances of the investigated elements were determined under the LTE approximation with the atmosphere models by Kurucz \& Castelli (2003). The stellar model was selected by means of a standard interpolation for $\mathrm{T}_{\mathrm{eff}}$ and $\log \mathrm{g}$. Elemental abundances were determined using the equivalent widths EWs and WIDH9 code by Kurucz. The latest version of the modified STARSP code (Tsymbal, 1996) and VALD line list (Kupka et al., 1999) were employed for the LTE determination of the abundances of $\mathrm{C}, \mathrm{Na}, \mathrm{Mg}, \mathrm{K}, \mathrm{Ba}, \mathrm{La}, \mathrm{Ce}, \mathrm{Pr}$, $\mathrm{Sm}$ and $\mathrm{Eu}$. The Eu abundance was calculated from the $\mathrm{Eu}$ II line $4129 \AA$ factoring in the HFS (Ivans et al., 2006). The carbon abundance was determined using the molecular synthesis fitting in the region of $\mathrm{CH}$ (4300-4330 $\AA \AA$ ).

For the $\mathrm{Na}, \mathrm{Mg}, \mathrm{K}$ and $\mathrm{Ba}$ abundances we used the NLTE corrections computed by Sergei Korotin: the NLTE correction for the employed $\mathrm{Ba}$ lines at $[\mathrm{Fe} / \mathrm{H}]$ close to -2 was about $0.1 \mathrm{dex}$ (Korotin et al., 2015); and the NLTE departures for $\mathrm{Na}, \mathrm{Mg}$ and $\mathrm{Al}$ at $[\mathrm{Fe} / \mathrm{H}] \sim-2.0$ varied from 0.03 to 0.2 dex depending on $\mathrm{T}_{\text {eff }}$ and $\log \mathrm{g}$ (Andrievsky et al., 2010); for $\mathrm{D}$ lines $\mathrm{Na} \sim 0.5$ dex.

The spectrum synthesis fitting of the $\mathrm{C}$ and $\mathrm{Ba}$ lines to the observed profiles for star is shown in Figs. 4,5.

To determine the systematic errors in the abundance estimates due to uncertainties in the atmospheric parameter determinations, we have derived the elemental abundances for the target star from several models with modified parameters $(\delta \mathrm{Teff}= \pm 100 \mathrm{~K} ; \delta \log \mathrm{g}= \pm 0.2 ; \delta \mathrm{Vt}= \pm 0.1)$. The total uncertainty due to the parameter and EW errors for the Fe I and Fe II are 0.11 and 0.12 , respectively. The determination accuracy for other elements varies from 0.10 to 0.18 dex.

We compared our abundance determinations with those obtained by other authors (Burris et al., 2001; Roederer et $a l ., 2014)$. The elemental abundances $[\mathrm{El} / \mathrm{Fe}]$ as a function of the relevant atomic numbers for HD 6268 are depicted in Fig. 6. 


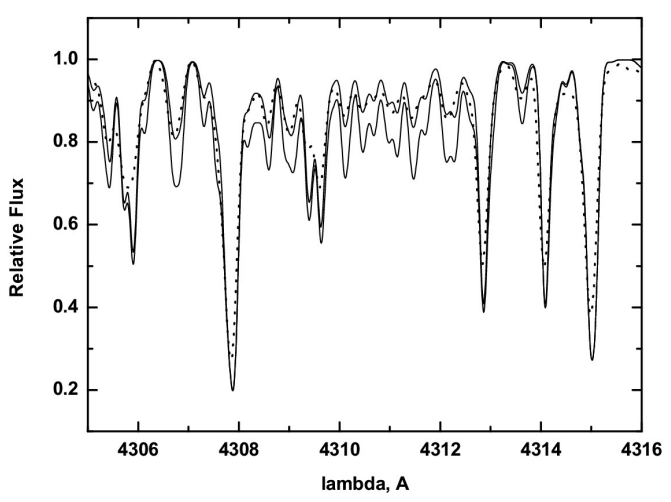

Figure 4: Observed (doted line) and calculated (solid lines) spectra in the region of $\mathrm{CH}$ lines

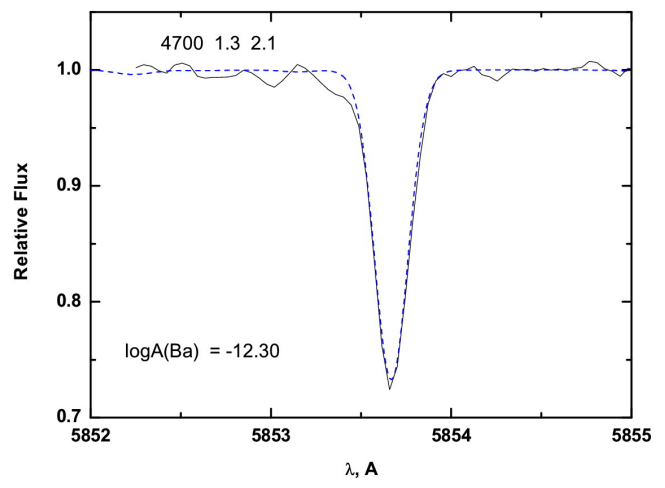

Figure 5: Observed (dashed line) and calculated (solid line) spectra in the region of Ba I line $5853 \AA$

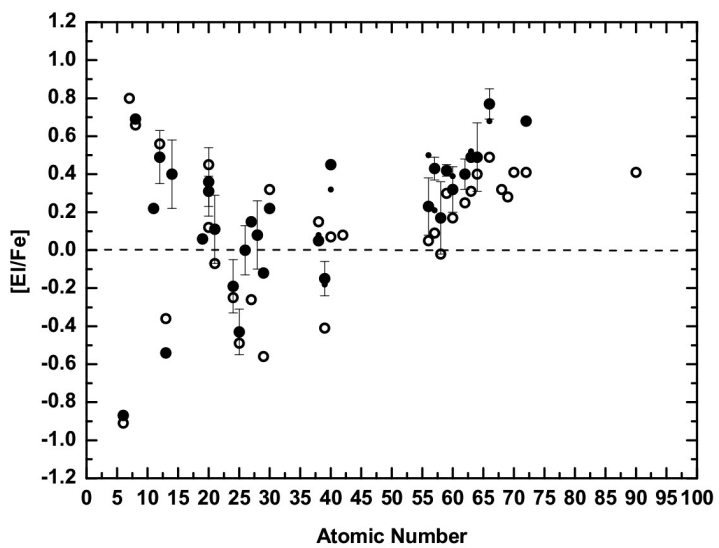

Figure 6: [El/Fe] vs. Atomic Number. Our determination marked as black circles, those of Burris et al. (2001) as small circles and Roederer et al. (2014) as open circles

\section{Results and discussions}

The study of HD 6258 star is important in two aspects: from the point of view of the advanced stages of stellar evolution of metal-deficient stars, and in the context of galactic chemical evolution.

\subsection{Stellar evolutionary effects (on $\mathrm{CNO}, \mathrm{Na}, \mathrm{Mg}, \mathrm{Al}$ )}

Stars in the advanced stages of their evolution exhibit variations in the abundances of certain chemical elements.
Table 2: $\mathrm{CNO}, \mathrm{Na}, \mathrm{Mg}, \mathrm{Al}$, and $\mathrm{Si}$ abundances

\begin{tabular}{|l|l|c|c|}
\hline Elem & our & $\begin{array}{c}\text { Roederer et al., } \\
\mathbf{2 0 1 4}\end{array}$ & $\begin{array}{c}\text { McWilliam et al., } \\
\mathbf{1 9 9 6}\end{array}$ \\
\hline$[\mathrm{C} / \mathrm{Fe}]$ & -0.87 & -0.91 & -0.68 \\
\hline$[\mathrm{O} / \mathrm{Fe}]$ & 0.69 & 0.66 & - \\
\hline $\mathrm{Na} / \mathrm{Fe}]$ & 0.12 & - & $0.22(\mathrm{LTE})$ \\
\hline$[\mathrm{Mg} / \mathrm{Fe}]$ & 0.49 & 0.56 & 0.44 \\
\hline$[\mathrm{Al} / \mathrm{Fe}]$ & $\mathbf{- 0 . 5 4}$ & $\mathbf{- 0 . 3 6}$ & $\mathbf{+ 0 . 4 8}$ \\
\hline$[\mathrm{Si} / \mathrm{Fe}]$ & 0.40 & - & 0.50 \\
\hline
\end{tabular}

In case of stars of the giant branch, a change in the abundances of $\mathrm{Li}, \mathrm{CNO}, \mathrm{Na}, \mathrm{Mg}$ and $\mathrm{Al}$ may be expected, which is the subject of many years research in the giants of globular clusters. Table 2 presents the abundances of the listed elements obtained in our study, as well as those reported in McWilliam et al. (1996) and Roederer et al. (2014).

The abundances are in good agreement with the only exception being the aluminium abundance, though it may be due to a misprint in the paper by McWilliam et al. (1996).

Gratton et al. (2000) carried out a detailed analysis of mixing along the red-giant branch in 62 field stars within the metallicity range of $-2 \leq[\mathrm{Fe} / \mathrm{H}] \leq-1$. The abundances of light elements in lower-RGB stars (i.e. stars brighter than those with the first dredge-up luminosity and fainter than the RGB bump) are in agreement with the predictions made using classical evolutionary models. A second dredge-up, which is a distinct mixing episode, occurs in most (perhaps in all) low mass metal-poor stars just after the RGB bump. In the field stars, this second mixing episode only reaches regions of incomplete CNO burning: it causes a depletion of the surface ${ }^{12} \mathrm{C}$ by about a factor of 2.5 with a corresponding increase in the $\mathrm{N}$ abundance by about a factor of 4 . However, any $\mathrm{O}-\mathrm{Na}$ anti-correlation which is typically found in the globular cluster stars is observed in the field stars.

Spite et al. (2006) performed an LTE analysis of 32 extreme metal-poor (EMP) giants in order to understand the CNO abundance variations found in some, but not all EMP field giants, considering mixing beyond the first dredge-up in the standard stellar models. They found out a $\mathrm{C}-\mathrm{N}$ anti-correlation that corroborated the hypothesis that the surface abundances could be modified by the $\mathrm{CNO}$ processed material from the inner regions.

Our findings, in particular, the carbon underabundance and nitrogen overabundance, may be consistent with the stellar evolution calculations and associated with canonical extra mixing (e.g., Denissenkov \& Pinsonneault, 2008; for the CMEP stars). In the mentioned paper, Fig. 5 illustrated variations in the surface $\mathrm{C}$ and $\mathrm{N}$ abundances (black curve) due to canonical extra mixing with the depth rmix $=0: 045 \mathrm{Rsol}$ and rate Dmix $=0: 04 \mathrm{~K}$ in the RGB model with $\mathrm{M}=0: 83 \mathrm{Msol}$ and $\mathrm{Z}=0$ 0:0001. Earlier, Denissenkov \& VandenBerg (2003) have shown that at least the extra mixing depth does not seem to depend strongly on metallicity. Therefore, they have suggested calling this universal non-convective mixing process "canonical extra mixing". They also hypothesised that some of the upper RGB stars (of GCs) may experience "enhanced extra mixing", which is much faster (by a factor of $~ 100$ ) and to a 
some extent deeper than canonical extra mixing. However, the proposed process of enhanced extra mixing leads to the depletion of oxygen and may also contribute to the O$\mathrm{Na}$ and $\mathrm{Mg}-\mathrm{Al}$ anti-correlations observed in some globular cluster red giants. The turbulent diffusion or/and rotationinduced meridional circulation may be an alternative mechanism of extra mixing in the upper RGB stars. In this case, enhanced extra mixing requires rotational velocities to be $\sim 10$ times as high as those which are sufficient for canonical extra mixing to occur.

The value $\log \mathrm{L} / \mathrm{L}_{\odot}=2.71$ for HD 6268 was calculated via the classical formula:

$$
\log \mathrm{L} / \mathrm{L}_{\odot}=\log \mathrm{M}^{*} / \mathrm{M}_{\odot}+4 \log \mathrm{Teff}^{*} / \mathrm{Teff}_{\odot}-\log \mathrm{g}^{*} / \mathrm{g}_{\odot}
$$

were Teff ${ }_{\odot}=5780 \mathrm{~K}, \log \mathrm{g}_{\odot}=4.44$ and assuming a stellar mass ${\stackrel{\odot}{*}=0.85 \mathrm{M}_{\odot} \text {. }}^{*}$

Figs. 7 and 8 illustrate the computations by Denissenkov \& Pinsonneault (2008) for canonical extra mixing at $\log \mathrm{L} / \mathrm{L}_{\odot}>2.2$ (these figures correspond to black curves in Figures 2 and 5 in the cited paper). If we compare our values of $[\mathrm{C} / \mathrm{H}]=-3.43$ and $\log \mathrm{L} / \mathrm{L}_{\odot}=2.71$ with the prediction reported in the afore-mentioned study, we can see that our star is located in the black curve which corresponds to canonical extra mixing for non-C-enhanced extremely metal-poor stars (Fig. 7).

If we adopt $[\mathrm{N} / \mathrm{Fe}]=0.8$ (Roederer et al., 2014) and $[\mathrm{C} / \mathrm{Fe}]=-0.87$ (our determination), these values are close to the black curve which shows variations in the surface $\mathrm{C}$ and $\mathrm{N}$ abundances due to canonical extra mixing (Fig. 8). The $\mathrm{C}$ and $\mathrm{N}$ abundances, as well as the luminosity of HD 6268 , corroborate the presence of canonical extra mixing (Denissenkov \& Pinsonneault, 2008) in this star.

We compared our data with those reported by Roederer et al. (2014) for the field giants with $[\mathrm{C} / \mathrm{Fe}]<-0.5$ for different relationships, such as $[\mathrm{Na} / \mathrm{Fe}]$ vs. $[\mathrm{O} / \mathrm{Fe}],[\mathrm{Na} / \mathrm{Fe}]$ vs. $[\mathrm{Al} / \mathrm{Fe}],[\mathrm{Al} / \mathrm{Fe}]$ vs. $[\mathrm{Mg} / \mathrm{Fe}]$ and $[\mathrm{Na} / \mathrm{Fe}]$ vs. $[\mathrm{Si} / \mathrm{Fe}]$. Our determinations fall into the area of the listed relations plotted using the values from Roederer et al. (2014); however, no clear correlations between these data can be seen, with the only exception being the $\mathrm{Al}-\mathrm{Mg}$ anti-correlation and to a smaller extent the $\mathrm{Na}-\mathrm{Al}$ anti-correlation. It should be noted that our data are in good agreement with the respective dependencies (the $\mathrm{Na}-\mathrm{O}$ correlations and $\mathrm{Al}$ - $\mathrm{Mg}, \mathrm{Na}-\mathrm{Al}, \mathrm{Si}$ anti-correlations) reported in Marino et al. (2015) for the globular cluster NGC 5286. Unfortunately, the number of observations is not sufficient to enable us to draw more reliable conclusions.

\subsection{Galactic enrichment}

The obtained pattern of the abundances of elements depending on their atomic numbers (for the elements with $\mathrm{AN}>50$, the abundance increases with increasing atomic number) is in agreement with the results obtained by Sneden et al. (2003) for the star CS 22892-052 exhibiting a scaled solar system r-process abundance (as stars with the main r-process); meanwhile, it is not consistent with the findings for HD 122563 (Honda et al., 2006) wherein an excess of light neutron-capture elements is observed without an enhancement of heavy elements (as stars with the weak r-process).

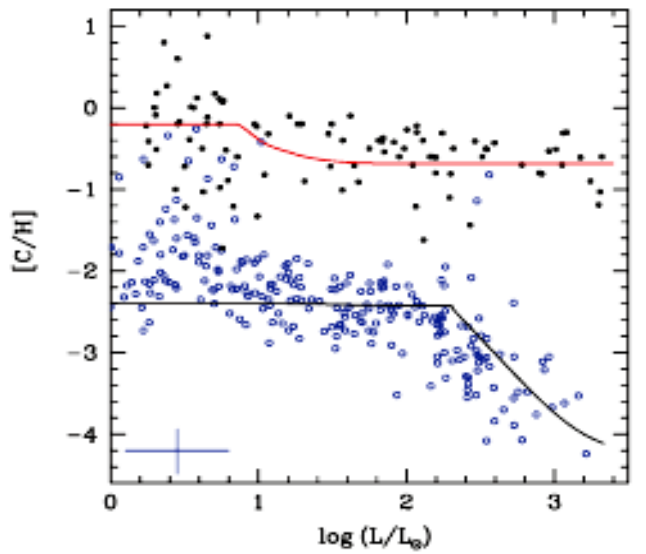

Figure 7: The carbon abundance vs. $\log \mathrm{L} / \mathrm{L}_{\odot}$; the figure corresponds to Figure 2 in Denissenkov\&Pinsonneault (2008)

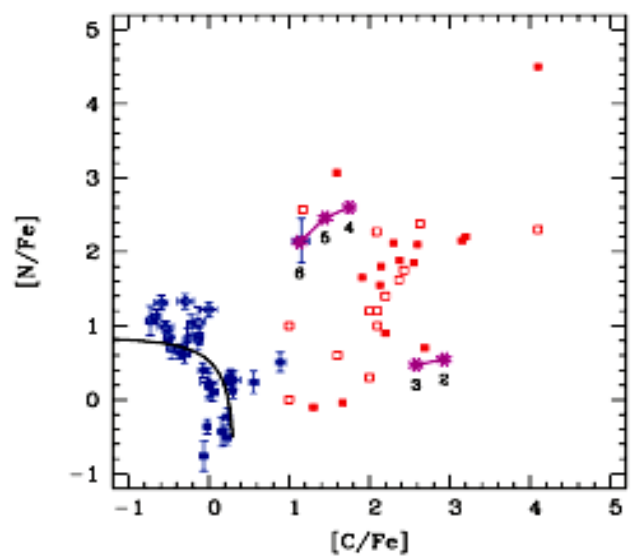

Figure 8: $[\mathrm{N} / \mathrm{Fe}]$ vs. $[\mathrm{C} / \mathrm{Fe}]$; the figure correspond to Figure 5 in Denissenkov\&Pinsonneault (2008). The black curve depicts variations in the surface $\mathrm{C}$ and $\mathrm{N}$ abundances associated with canonical extra mixing with the depth rmix 0.045 Rsun and rate Dmix $=0.04 \mathrm{~K}$ in the RGB model with $\mathrm{M}=0.83 \mathrm{M}_{\odot}$ and $\mathrm{Z}=0.0001$.

\section{Conclusion}

- The $\mathrm{C}$ and $\mathrm{N}$ abundances confirm their changes due to canonical extra mixing (Denissenkov \& Pinsonneault, 2008).

- The Na-O correlation is open to question unlike the $\mathrm{Na}-\mathrm{Si}$ correlation which is likely to exist.

- The correlations between $\mathrm{Al}-\mathrm{Mg}$ and $\mathrm{Al}-\mathrm{Na}$ confirm the data obtained for the field giants (Roederer et al., 2014).

- According to the distribution of elements depending on their atomic numbers, HD 6268 is a metal-poor main r-process enriched star.

\section{References}

Andrievsky S.M. et al.: 2010, $A \& A, \mathbf{5 0 9}$, id. A88.

Asplund M.: 2005, ARA\&A, 43, 481.

Burris et al.: 2000, ApJ 554, 302.

Castelli \& Kurucz: 2004, ArXiv Astrophysics e-prints astro-ph/0405087. 
Cenarro et al.: 2007, MNRAS, 374, 664.

Charbonnel C.: 1994, A\&A, 282, 811.

Charbonnel C.: 1995, ApJ, 453, 41.

Demarque et al.: 2004, ApJS, 155, 667.

Denissenkov P.,Pinsonneault:2008, ApJ 679, 1541.

Denissenkov P., VandenBerg D.A.: 2003, ApJ, 593, 509.

Gaia Collaboration: 2018, Gaia DR2, Cat.1345.

Galazutdinov G.: 2007, http://gazinur.com/DECHsoftware.html.

Gratton, R.: 1989, $A \& A$ 208, 171.

Francois P.: 1996, $A \& A$ 213, 229.

Frebel et al.: 2008, ApJ, 684, 588 .

Honda et al.: 2006, ApJ, 643, 1180.

Iben I.: 1964, ApJ, 140, 1631.

Ivans et al.: 2006, ApJ, 645, 613 .

Korotin et al.: 2015, $A \& A \mathbf{5 8 1}, 70$.
Lind et al.: 2012, MNRAS, 427, 50.

McWilliam et al.: 1995, $A J, \mathbf{1 0 9}, 2757$.

Kupka et al.: 1999, A\&ASuppl., 138, 119.

Marino et al.: 2015, MNRAS, 450, 815 .

Pilachowski et al.: 1996, AJ, 111, 1689.

Placco et al.: 2014, ApJ, 797, 21.

Roederer et al.: 2014, $A J$, 147, 136.

Sneden et al.: 2003, ApJ, 591, 936.

Spite et al.: 2006, $A \& A, \mathbf{4 5 5}, 291$.

Thévenin, F., Idiart, T. P.: 1999, ApJ, 521, 753.

Tsymbal V.: 1996, ASP Conf. Ser., 108, 198.

VandenBerg D., Smith G.: 1988, PASP, 100, 314.

Wu et al.: 2015, $A \& A, \mathbf{5 7 9}, \mathrm{A} 8$.

Yong et al.: 2013, ApJ, 762, 26.

Zacharias et al.: 2012, The fourth US Naval Observatory CCD Astrograph Catalog (UCAC4). 